\title{
Morphology and development of a novel murine skeletal dysplasia
}

\author{
Marta Marchini ${ }^{\text {Corresp., 1, } 2 \text {, Elizabeth Silva Hernandez }}{ }^{3}$, Campbell Rolian ${ }^{\text {Corresp. 2, } 3}$ \\ ${ }^{1}$ Department of Anatomy and Cell Biology, Cumming School of Medicine, University of Calgary, Calgary, Canada \\ 2 McCaig Institute for Bone and Joint Health, University of Calgary, Calgary, Canada \\ 3 Department of Comparative Biology and Experimental Medicine, Faculty of Veterinary Medicine, University of Calgary, Calgary, Canada \\ Corresponding Authors: Marta Marchini, Campbell Rolian \\ Email address: mmarchin@ucalgary.ca, cprolian@ucalgary.ca
}

Background: Limb bones develop and grow by endochondral ossification, which is regulated by specific cell and molecular pathways. Changes in one or more of these pathways can have severe effects on normal skeletal development, leading to skeletal dysplasias. Many skeletal dysplasias are known to result from mis-expression of major genes involved in skeletal development, but the etiology of many skeletal dysplasias remains unknown. We investigated the morphology and development of a mouse line with an uncharacterized mutation exhibiting a skeletal dysplasia-like phenotype (Nabo).

Methods: We used $\mu \mathrm{CT}$ scanning and histology to comprehensively characterize the phenotype and its development, and to determine the developmental stage when this phenotype first appears.

Results: Nabo mice have shorter limb elements compared to wildtype mice, while clavicles and dermal bones of the skull are not affected. Nabo embryos at embryonic stage E14 show shorter limb cartilage condensations. The tibial growth plate in Nabo mice is wider than in wildtype, particularly in the proliferative zone, however proliferative chondrocytes show less activity than wildtype mice. Cell proliferation assays and immunohistochemistry against the chondrogenic marker Sox9 suggest relatively lower, spatially-restricted, chondrocyte proliferation activity in Nabo. Bone volume and trabecular thickness in Nabo tibiae are also decreased compared to wildtype.

Discussion: Our data suggest that the Nabo mutation affects endochondral ossification only, with the strongest effects manifest in more proximal limb structures. The phenotype appears before embryonic stage E14, suggesting that outgrowth and patterning processes may be affected. Nabo mice present a combination of skeletal dysplasia-like characteristics not present in any known skeletal dysplasia. Further genomic and molecular analysis will help to identify the genetic basis and precise developmental pathways involved in this unique skeletal dysplasia 
1

2

3

4

5

6

7

8

9

10

11

12

13

14

15

16

17

18

19

20

21

22

23

24

25

1

\section{8}

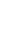

Title:

Morphology and development of a novel murine skeletal dysplasia

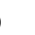

7

8

.

0

12

3

4

$$
{ }^{1} \text { Department of Anatomy and Cell Biology, Cumming School of Medicine, University of }
$$

Calgary

${ }^{2}$ McCaig Institute for Bone and Joint Health, University of Calgary

${ }^{3}$ Department of Comparative Biology and Experimental Medicine, Faculty of Veterinary Medicine, University of Calgary

Address for correspondence:

HRIC 3AC68 - 3330 Hospital Dr NW

Calgary, AB T2N0L8

Email: cprolian@ucalgary.ca 


\section{Abstract}

Background: Limb bones develop and grow by endochondral ossification, which is regulated by specific cell and molecular pathways. Changes in one or more of these pathways can have severe effects on normal skeletal development, leading to skeletal dysplasias. Many skeletal dysplasias are known to result from mis-expression of major genes involved in skeletal development, but the etiology of many skeletal dysplasias remains unknown. We investigated the morphology and development of a mouse line with an uncharacterized mutation exhibiting a skeletal dysplasia-like phenotype (Nabo).

Methods: We used $\mu \mathrm{CT}$ scanning and histology to comprehensively characterize the phenotype and its development, and to determine the developmental stage when this phenotype first appears.

Results: Nabo mice have shorter limb elements compared to wildtype mice, while clavicles and dermal bones of the skull are not affected. Nabo embryos at embryonic stage E14 show shorter limb cartilage condensations. The tibial growth plate in Nabo mice is wider than in wildtype, particularly in the proliferative zone, however proliferative chondrocytes show less activity than wildtype mice. Cell proliferation assays and immunohistochemistry against the chondrogenic marker Sox9 suggest relatively lower, spatially-restricted, chondrocyte proliferation activity in Nabo. Bone volume and trabecular thickness in Nabo tibiae are also decreased compared to wildtype.

Discussion: Our data suggest that the Nabo mutation affects endochondral ossification only, with the strongest effects manifest in more proximal limb structures. The phenotype 
49 affected. Nabo mice present a combination of skeletal dysplasia-like characteristics not present 50 in any known skeletal dysplasia. Further genomic and molecular analysis will help to identify the 51 genetic basis and precise developmental pathways involved in this unique skeletal dysplasia. 52

53

54

55 
56

57

58

59

60

61

62

63

64

65

66

67

68

69

70

71

72

73

74

75

76

77 78

\section{Introduction}

The mammalian skeleton develops primarily through two mechanisms: endochondral ossification and intramembranous ossification. In endochondral ossification, a developing bone is preceded by formation of a cartilaginous model, or anlage, within which mesenchymal cells differentiate into chondrocytes (Eames, de la Fuente \& Helms, 2003). This cartilage anlage is then replaced with bone, which grows longitudinally under the control of the growth plate (Kronenberg, 2003). In intramembranous ossification, direct differentiation of osteoblasts from mesenchymal cells results in direct apposition of bone without a cartilaginous model (Hall, 2005). Disruption of these mechanisms can produce severe phenotypes with defects in both endochondral and intramembranous ossification (Eames, de la Fuente \& Helms, 2003; Krakow \& Rimoin, 2010). Clinically, these phenotypes are collectively known as skeletal dysplasias (Rimoin et al., 2007).

Skeletal dysplasias (SDs) disrupt normal formation and development of bone (osteodysplasia), cartilage (chondrodysplasia), or both (Beals \& Horton, 1995). As SDs are often the result of disruptions in major signaling pathways (Rimoin et al., 2007), SDs can show abnormal phenotypes in multiple tissues, alone or in combination, including limb and skull defects (Ballock \& O’Keefe, 2003; Shah, Varghese \& Fernandes, 2016), kyphosis, scoliosis and other vertebral anomalies (Shirley \& Ain, 2012), as well as defects in other organ systems (Krakow \& Rimoin, 2010). Together, these disorders affect between 2 and 4 live births per 10,000 (Orioli, Castilla \& Barbosa-Neto, 1986; Stoll et al., 1989) with high perinatal mortality rates (Barbosa-Buck et al., 2012), short life expectancy, and lifelong disability (Baker et al., 1997), although long term prognosis depends on the type of dysplasia (Krakow \& Rimoin, 2010). The genetic cause of many dysplasias remains unknown (Srinivas \& Shapiro, 2012). 
During an experiment selecting for increased tibia length in mice (Marchini et al., 2014),

80

81

82 we discovered mice with a previously unreported short-limbed phenotype. Strong selection in relatively small populations can increase the frequency of rare genetic variants, leading to higher proportions of homozygotes (Marsden et al., 2016). We believe that this may have facilitated the appearance of this short limb phenotype. In this study, we investigate the morphology, bone and cartilage histology, and growth of this short-limbed mouse line, and discuss the potential cell mechanisms of bone and cartilage growth that lead to this peculiar phenotype.

.

\section{Materials and methods}

\section{Sample collection}

All experimental procedures were approved by the Health Sciences Animal Care Committee at the University of Calgary (protocol AC13-0077), and conducted in accordance with best practices outlined by the Canadian Council on Animal Care. The Nabo mouse, and the Longshanks mouse it originated from, are derived from Hsd-ICR (CD-1®) outbred stock (Harlan Biosciences, Indianapolis, IN). Mice are housed in individually ventilated cages (Greenline Sealsafe PLUS, Buguggiate, Italy), kept on a 12-hour light/dark cycle at a constant room temperature $\left(20^{\circ} \mathrm{C}\right)$, with food (Pico-Vac Mouse Diet 5061, LabDiet, St. Louis, MO) and water provided ad libitum.

Nabo first appeared in generation F14 of the Longshanks selective breeding experiment. This selection experiment consists of three independent lines of CD-1 mice bred under similar conditions for the same number of generations: two lines selectively bred for long tibiae relative to body mass (Longshanks 1 and Longshanks 2), and a random-bred control line (wildtype) (Marchini et al., 2014). Longshanks mice at generation F14 showed an increase of 9-13\% in 
102 tibia length relative to body mass over wildtype. For additional information see Marchini et al.

103 (2014) (Marchini et al., 2014). We discovered four siblings (two females and two males) from a

104 litter of eight (line Longshanks 2, family O2) with short limbs. After a generation (F15), we

105 identified two more females with a similar phenotype in a related family (line Longshanks 2,

106 family $\mathrm{H} 2$ ). We named this phenotype and these mice Nabo. By mating a Nabo $\mathrm{O} 2$ male and

107 Nabo $\mathrm{H} 2$ female, we were able to generate a litter (family Nabo01) of three mice (see pedigree,

108 Figure S1). We then paired a Nabo H2 female with a wildtype male and two Nabo01 males with

109 wildtype females. This produced three litters of mice without the Nabo phenotype (called

110 Nabo1A, Nabo3A and Nabo4A). We crossbred these mice to produce litters of mice with

111 approximately $10 \%$ Nabo mouse phenotype, while the remaining mice were without phenotype

112 (Figure S1). Nabo mice were then inbred to obtain litters with exclusively Nabo phenotype. For

113 all analyses, we used wildtype from the Longshanks experiment, and Nabo mice derived from

114 Longshanks 2 (Marchini et al., 2014). Mice at selected ages were euthanized and stored at $-20^{\circ} \mathrm{C}$

115 or immediately processed as needed (see below).

116

\section{Postnatal growth curve and $\mu$ CT scanning}

118 To determine the extent, timing and pattern of skeletal growth retardation in Nabo mice,

119 we used $\mu \mathrm{CT}$ scanning to measure the length of skull, clavicle, scapula, humerus, ulna, $5^{\text {th }}$

120 metacarpal, femur, tibia and $5^{\text {th }}$ metatarsal of five short and five wildtype mice for each postnatal

121 (P) age P0, P3, P7, P9/P10, P14, P21, P28, P42, P75, P100, and P125. Whole carcasses were

122 thawed at room temperature and scanned using a Skyscan $1173 \mu \mathrm{CT}$ scanner (Bruker, Kontich,

123 Belgium), using appropriate scan parameters for the size of each mouse (voxel size range $30 \mu \mathrm{m}$ -

$12471 \mu \mathrm{m}$, x-ray $70-80 \mathrm{kV}, 80-100 \mu \mathrm{A}$, no filter). Scans were reconstructed as tomographic stacks 
125 using NRECON v1.6.9 (Bruker, Kontich, Belgium) and linear measurements were taken via 3D

126 landmarking in Amira v.5.4.2 (Visage Imaging, Berlin, Germany) as described (Cosman,

127 Sparrow \& Rolian, 2016; Farooq et al., 2017). Growth curves for each element were obtained by

128 fitting the cross-sectional data with Gompertz logistic growth functions (German et al., 1994).

129 Growth rates were obtained by taking the first derivative of the fitted growth curves (Farooq et

130 al., 2017; Marchini \& Rolian, 2018).

131 To assess whether endochondral and/or intramembranous elements in the skull were

132 affected, we $\mu$ CT scanned five P75 Nabo and five age-matched wildtypes (three males and two

133 females in each group) (voxel size $45 \mu \mathrm{m}$, x-ray $70-80 \mathrm{kV}, 80-100 \mu \mathrm{A}$ ) and took the following

134 linear measurements of individual skull elements: length and width of the occipital and palatine

135 bones, length of parietal, frontal, nasal bones, sphenoid and total length of the skull from the

136 foramen magnum to the rostral tip of the nasal bone (Figure S2). Linear measurements were

137 made via 3D landmarking in Amira v.5.4.2.

138

139 Embryonic growth

140 To investigate when in development the Nabo phenotype is first apparent, we measured

141 the humerus, ulna, femur and tibia of Nabo and wildtype embryos ( $\mathrm{n}=5-6$ each) at developmental

142 stages E14 and E18. For E14, we used iodine contrast-enhanced $\mu$ CT scanning (Gignac et al.,

143 2016), while for E18 we used whole-mount Alcian blue/Alizarin red staining.

144 E14 embryos were harvested, placed in 1x PBS on ice and fixed in 10\% neutral-buffered

145 formalin. After fixation, embryos were placed in Lugol's iodine stain $\left(0.375 \% \mathrm{I}_{2}\right.$ and $0.75 \% \mathrm{KI}$

146 in $\mathrm{dH}_{2} \mathrm{O}$ ). Lugol's iodine stains soft tissues for visualization with $\mu \mathrm{CT}$ scanning in a time and

147 concentration dependent manner (Gignac et al., 2016), but does not stain cartilage, leaving a 
148 negative space on 3D renderings (Figure S3), which can be digitally segmented. After several

149 days, embryos were embedded in $1 \%$ agarose and scanned using the Skyscan $1173 \mu \mathrm{Ct}$ scanner

150 (voxel size $7 \mu \mathrm{m}$, x-ray $65-70 \mathrm{KV} ; 85-96 \mu \mathrm{A}$, no filter). Scans were reconstructed as above. We

151 then volumized the humerus, ulna, femur and tibia (Figure S3) and calculated linear

152 measurements from the resulting surface models by placing landmarks on their proximal and

153 distal ends via 3D landmarking as above. To standardize cartilage measurements, we took linear

154 measurements of the mediolateral width of the nose (nostril to nostril) and the mean interorbital

155 distance and used them as covariates in our statistical analyses. To assess qualitatively any

156 cellular disruption of the cartilage anlagen in the hind limb, we collected hind limbs of Nabo and

157 an age-matched wildtype at embryonic stage E14.5 (Figure S4). Hind limbs were fixed in 4\%

158 paraformaldehyde (Sigma) overnight at $4^{\circ}$ C. Samples were then dehydrated, embedded in

159 paraffin, and sectioned in the coronal plane at $4 \mu \mathrm{m}$. Sections were deparaffinized in xylene,

160 stained with Mayer's hematoxylin (Sigma), 1\% Alcian blue in 1\% acetic acid (Sigma), 1\%

161 Phosphomolybdic acid (Sigma), 0.5\% Sirius red (Direct Red 80, Sigma) in 0.5\% acetic acid and

162 then cover slipped. The stained sections were imaged using a digital microscope (Axioplan 2,

163 Zeiss) with attached camera (Optronics), using StereoInvestigator v7.

164 E18 fetal mice were harvested and placed in PBS on ice. The embryos were then skinned

165 and internal organs were removed. The mice were then placed in ice-cold $95 \%$ ethanol for one

166 hour. The samples were left on a shaker overnight in $95 \%$ ethanol at room temperature. We

167 stained the embryos overnight at room temperature using a staining solution of Alcian blue $8 \mathrm{GX}$

168 (Sigma) and Alizarin red (Sigma) (staining solution: $5 \mathrm{ml}$ of 0.4\% Alcian blue in 70\% ethanol,

$1695 \mathrm{ml}$ glacial acetic acid, $70 \mathrm{ml}$ of $95 \%$ ethanol, $20 \mathrm{ml}$ of water; working solution: $100 \mu 1$ of $0.5 \%$

170 Alizarin red (Sigma) added to $10 \mathrm{ml}$ of staining solution). After staining overnight, we rinsed the 
171 embryos in water and dissolved soft tissues in $2 \% \mathrm{KOH}$ for approximately eight hours. We then

172 placed the samples in $0.25 \% \mathrm{KOH}$ for 30 minutes and cleared tissues in increasing concentration

173 of glycerol in $0.25 \% \mathrm{KOH}$. Samples were stored in $50 \%$ glycerol $/ 0.25 \% \mathrm{KOH}$. Specimens were

174 photographed with a scale using a Nikon SMZ1500 stereomicroscope linked to a Nikon D200

175 DSLR camera. We then took linear measurements of the bones using ImageJ v1.48 (Schneider,

176 Rasband \& Eliceiri, 2012).

177

178 Histomorphometry

179 To analyze growth plate morphology and characterize any cellular disruption of endochondral 180 ossification, we collected sixteen wildtype tibiae and eleven Nabo tibiae from mice at postnatal 181 age P14. Tibiae were fixed in $4 \%$ paraformaldehyde (Sigma) for 4 to 5 days at $4{ }^{\circ} \mathrm{C}$, and 182 decalcified using Poly-NoCal (Polysciences, Inc). Proximal tibial growth plates were dehydrated, 183 embedded in paraffin, and sectioned in the coronal plane at $5 \mu \mathrm{m}$. Sections were deparaffinized 184 in xylene, stained with Mayer's hematoxylin (Sigma), 1\% Alcian blue in 1\% acetic acid (Sigma), 185 1\% Phosphomolybdic acid (Sigma), 0.5\% Sirius red (Direct Red 80, Sigma) in 0.5\% acetic acid 186 and then cover slipped. The stained sections were imaged at $5 \mathrm{x}$ using a digital microscope 187 (Axioplan 2, Zeiss) with attached camera (Optronics) using StereoInvestigator v7. We selected a 188 coronal section of the growth plate approximately halfway along the cranio-caudal axis for each 189 specimen. In each section, we measured the total growth plate height (from epiphyseal to 190 metaphyseal borders), resting/proliferative and hypertrophic zone heights at 5x magnification.

191 For each variable, we repeated measurements 10 times evenly spaced across the section and took

192 the average of these measurements. We identified the boundary between the zones based on the 193 organization and size of the chondrocytes, as follows: the proliferative zone was considered as 
194 the zone with chondrocytes organized into columns and the resting zone as the zone proximal to

195 the proliferative zone with sparse chondrocytes not organized in columns. The hypertrophic zone

196 was determined based on the increased volume of the chondrocytes and reduced presence and

197 staining of extracellular matrix. We also measured the height, in the direction of longitudinal

198 growth, of at least ten terminal hypertrophic chondrocytes, adjacent to the chondro-osseous

199 junction, at 20x magnification in nine Nabo mice and seven wildtype mice. Linear measurements

200 were taken using the "Straight Line" tools in ImageJ v1.48 (Schneider, Rasband \& Eliceiri,

201 2012). We calculated the means of the measures taken in different regions of the growth plate for 202 each individual before statistical analysis.

203

204 Cell proliferation assay

205 To assess whether the dysplasia was associated with altered activity of the proliferative 206 chondrocytes in the proximal growth plate, we injected three specimens of Nabo and eight 207 wildtype mice intraperitoneally with 5-Bromo-2'-deoxyuridine (Sigma) in PBS at 50 $\mu \mathrm{g} / \mathrm{g}$ of 208 body weight (Wojtowicz \& Kee, 2006). 5-Bromo-2'-deoxyuridine (BrdU) is incorporated into 209 DNA during the S phase of the cell cycle (Wojtowicz \& Kee, 2006). P14 mice were euthanized 21024 hours after BrdU injection. Tibiae were harvested, and fixed in 10\% Neutral Buffered 211 Formalin (Sigma) and decalcified using Cal-Ex ${ }^{\text {TM }}$ II (Fisher Scientific). The proximal tibial 212 growth plates of all specimens were dehydrated, embedded in paraffin, and sectioned in the 213 coronal plane at $8 \mu \mathrm{m}$. Sections were deparaffinized in xylene, treated with $0.5 \%$ pepsin $/ 0.05 \mathrm{HCl}$

214 (Sigma) and hydrogen peroxide (3\% in methanol) to block endogenous peroxidase. Sections 215 were then blocked with 10\% goat serum/1\%BSA/PBS for an hour at room temperature and 216 incubated with rat monoclonal anti-BrdU antibody $(1: 100, \mathrm{AbD}$ Serotec $)$ overnight at $4^{\circ} \mathrm{C}$. After 
217 washes, the sections were incubated with biotinylated anti-rat $\operatorname{IgG}(1: 200$, Vector Laboratories)

218 for an hour, and treated with streptavidin horseradish. Liquid DAB substrate kit was used to

219 detect the BrdU signal (Invitrogen), and hematoxylin was used as a counterstain. We selected the

220 coronal section of the growth plate closest to the center of the bone along the cranial-caudal axis

221 for each specimen. Sections were imaged at $5 \mathrm{x}$ as above.

222

223 Immunohistochemistry

224 To determine whether transcriptional regulation within the growth plate had been

225 disrupted, we performed immunohistochemistry for Sox9 and Runx2, two transcription factors

226 important for cell proliferation and hypertrophic differentiation, respectively. We used the same

227 specimens used for the proliferation assay. Sections were deparaffinized in xylene, treated with

228 hydrogen peroxide (15 minutes, 3\% in methanol) to block endogenous peroxidase, and followed

229 by antigen retrieval (30 minutes, $0.1 \%$ Triton-X). Sections were then blocked with normal serum

230 for an hour at room temperature and incubated with anti-Sox9 primary antibody (1:300, AF3075,

231 Bio-Techne) and anti-Runx2 primary antibody (1:400, ab192256, AbCam) overnight at $4^{\circ} \mathrm{C}$.

232 After washes, the sections were incubated with HRP-conjugated secondary antibodies (Sox9:

233 Bio-Techne HAF109, 1:100, Runx2: AbCam ab6721, 1:100) for an hour. Liquid DAB substrate

234 kit (Invitrogen) was used to detect Sox9 and Runx2 and methyl green was used as a counterstain.

237 Cortical and trabecular analysis

238 To determine whether the Nabo have altered cortical and trabecular morphology in

239 addition to their abnormal external skeletal morphology, we dissected and $\mu \mathrm{CT}$ scanned the right 
240 tibia from five P75 Nabo (three females and two males) and four age-matched wildtype (two

241 females and males) (voxel size range 7.10-8.52, x-ray 75-78KV; $100 \mu \mathrm{A}$, no filter). We first

242 analyzed tibia diaphyseal cross-sectional properties, to determine whether cortical bone

243 morphology differed between groups (Nabo and wildtype). Cross-sectional image stacks were

244 imported into Fiji (ImageJ v1.50e) (Schindelin et al., 2012); we selected the tenth image, or

245 approximately 80 microns, proximal to the tibia-fibula junction. We then used the plugin BoneJ

246 (Doube et al., 2010) to measure the cross-sectional area (CSA), polar section modulus ( $\left.\mathrm{Z}_{\mathrm{pol}}\right)$, and

247 mean cortical thickness (MT) of the tibia. We calculated the index of robusticity (IR) of the bone

248 by taking the polar section modulus $\left(\mathrm{Z}_{\mathrm{pol}}\right)$ to the product of bone length and body mass (in $\left.\mathrm{mg}^{2 / 3}\right)$

249 (Cosman, Sparrow \& Rolian, 2016). Measurements of trabecular bone were performed in BoneJ

250 in each tibia from the first image showing trabeculae distal to the partially fused growth plate,

251 and extending $1 \mathrm{~mm}$ distally. We measured bone volume (BV), total volume (TV), bone volume

252 fraction (BV/TV), trabecular thickness (Tb.Th), and tibia length as above.

253

254 Statistical analysis

255 Measurements for the postnatal growth curve were analyzed using analysis of covariance

256 (ANCOVA) with skull, clavicle, scapula, humerus, ulna, $5^{\text {th }}$ metacarpal, femur, tibia, and $5^{\text {th }}$

257 metatarsal lengths as dependent variables, line (Nabo vs wildtype) as categorical factors, and

258 body mass as a covariate. Measurements of the skull elements at P75 were analyzed using

259 ANCOVA using length and width of the elements as dependent variables and body mass as a

260 covariate.

261 Cortical and trabecular bone variables were analyzed using ANOVA, with mouse line as

262 categorical factor. Measurements of humerus, ulna and tibia length at E18 were analyzed using 
263 ANOVA. Measurements of the bone elements at E14 were analyzed using ANCOVA using

264 humerus, ulna, radius, femur and tibia length as dependent variables and mean width of the eyes 265 and width of nose as covariates.

266 Means from the histomorphometry data measurements were analyzed using ANCOVA

267 with proximal growth plate height, the heights of the resting, proliferative and hypertrophic

268 zones, and last hypertrophic chondrocyte height as dependent variables, line as categorial factor, 269 and body mass as covariate.

270 All statistical analyses were performed using SPSS v23 (IBM Corp. Released 2015. IBM

271 SPSS Statistics for Macintosh, Version 23.0. Armonk, NY: IBM Corp), and differences in means

272 between the groups were considered statistically significant at $\mathrm{p}<0.05$.

273

274 Results

275 The Nabo mice

276 Nabo mice are characterized by short, bowed forelimb and hind limb bones, with more

277 pronounced shortening of the more proximal elements (stylopod and zeugopod) (Figure 1).

278 There is sometimes an extra thoracic vertebra accompanied by paired, or occasionally unilateral,

279 ribs that express either as false ribs, or as true ribs with an extra sternal segment (Figure 1c,

280 Figure 2b). Nabo mice are fertile, with viable litters. The litters are generally small, between 5

281 and 8 pups (vs. 12-15 for wildtype), and are weaned several days later than the wildtype mice

282 due to the small size of the animals.

283

284 Nabo postcranial phenotypes and growth 

postnatal development contributes to the Nabo phenotype. We chose skeletal elements that

287 develop by endochondral ossification (e.g. femur, tibia, ulna), intramembranous ossification (e.g.

288 clavicle) or a combination of both (e.g. skull) and compared them to CD1 wildtype mice.

289 Clavicle size does not differ during post-natal growth (Figure 3, Table S1). Skull growth rates 290 are also very similar, producing a skull that is approximately $5.3 \%$ shorter in Nabo than in the 291 wildtype group at P125. Humerus, ulna, femur and tibia are significantly different across all 292 post-natal ages, showing respectively $22.7 \%, 22.9 \%, 20.8 \%$ and $26.9 \%$ reduction in element size 293 compared to age-matched wildtype mice at P125 (Figure 3, Table S1). The scapula at P125 also 294 shows a $25.5 \%$ reduction in element size compared to age-matched wildtype mice, and the length 295 is significantly different for all post-natal stages except for P28 where the $p$-value is $p=0.085$ 296 (ANCOVA, see Table S1 for details) (Figure 3). The autopod (hand and foot) is not affected as 297 much as the stylopod and zeugopod: the fourth metacarpal and the metatarsal are shorter by $9.6 \%$ 298 and $8.7 \%$ at P125. Metacarpal length is significantly different from wildtype only at P28 299 (ANCOVA, F=9.190, p=0.019) and P125 (ANCOVA, F=8.993, p=0.024) while metatarsal 300 length is significantly different from wildtype at P75 (ANCOVA, F=12.147, p=0,025) and P100 301 (ANCOVA, $\mathrm{F}=9.414, \mathrm{p}=0.022$ ).

302

303 Nabo craniofacial phenotype $\mu \mathrm{CT}$ scans of Nabo skulls show no evident deformities such as tooth or jaw 305 dysmorphologies, cleft palate, or other abnormal facial phenotypes (Figure S2). Since the growth 306 rate of the skull at age P75 is close to 0 (Figure 3), we took linear measurements of several dorsal 307 and ventral bones of the skull of five Nabo and five wildtype mice at postnatal age P75 (three 
308 males and two females each) from the $\mu \mathrm{CT}$ scans. We did not find any differences in the length

309 of cranial vault bones that develop by intramembranous ossification, including parietals, frontals

310 and nasal bones (de Beer, 1937) (Table 1, Figure S2). The foramen magnum is significantly

311 smaller in dorsoventral diameter by $6.5 \%$ (ANCOVA, $\mathrm{F}=6.046, \mathrm{p}=0.044$ ) and in width by $14 \%$

312 (ANCOVA, $\mathrm{F}=54.363, \mathrm{p}<0.001$ ). We also measured the length from the most dorsal landmark

313 on the border of the foramen magnum to the most rostral landmark on the median internasal

314 suture and found that the skull is significantly shorter than wildtype mice by $6.2 \%$ (ANCOVA,

$315 \mathrm{~F}=35.339, \mathrm{P}=0.001$ ), similar to the data from $\mathrm{P} 125$ mice (Table 1, Figure $\mathrm{S} 2$ ). The

316 measurements of the cranial base show that the occipital bone and sphenoid, which develop in

317 part by endochondral ossification (de Beer, 1937), are reduced in size, with the former narrower

318 by $21.2 \%$ (ANCOVA, $\mathrm{F}=69.294, \mathrm{p}<0.001$ ) and shorter by 19.7\% (ANCOVA, $\mathrm{F}=125.170$,

$319 \mathrm{p}<0.001$ ), and the latter shorter by $24.6 \%$ (ANCOVA, $\mathrm{F}=7.778, \mathrm{p}=0.0027$ ) (Table 1, Figure $\mathrm{S} 2$ ).

320 In comparison, the palatine, which develops by intramembranous ossification (de Beer, 1937),

321 does not differ in size between Nabo and wildtype mice.

322

323 Developmental timing of Nabo phenotype

324 To investigate the developmental timing of the appearance of the Nabo phenotype, we

325 measured the size of the diaphysis of the tibia, humerus and ulna for Nabo and wildtype embryos

326 at developmental stage E18. Nabo mice at this stage have a significantly shorter diaphysis in the

327 humerus ( $46.8 \%$ shorter than wildtype) (ANOVA, $\mathrm{F}=119.463, \mathrm{p}<0.001$ ), ulna (30.7\%)

328 (ANOVA, $\mathrm{F}=58.191, \mathrm{p}<0.001$ ), femur (35.8\%) (ANOVA, $\mathrm{F}=44.173, \mathrm{p}<0.001)$, tibia (19.8\%)

329 (ANOVA, $\mathrm{F}=16.096, \mathrm{p}=0.004$ ), and in the body of the scapula (52.2\%) (ANOVA, $\mathrm{F}=114.993$,

$330 \mathrm{p}<0.001$ ) (Figure 2 and Table 2). We then measured the length of the cartilage anlagen for the 
331 femur, tibia, humerus, ulna and radius of embryos stained with Lugol's solution at embryonic

332 stage E14. Femur, tibia, humerus and ulna were shorter in Nabo mice compared to wildtype mice

333 by respectively 39.3\% (ANCOVA, $F=6.521, p=0.043), 33.3 \%(A N C O V A, F=6.276, p=0.046)$,

$33434.5 \%(\mathrm{ANCOVA}, \mathrm{F}=24.695, \mathrm{p}=0.003)$ and 33.4\% (ANCOVA, $\mathrm{F}=10.935, \mathrm{p}=0.016)$. Length

335 differences remain present after controlling for covariation with internasal distance and

336 interorbital distance (see Table 3 for details, Figure S3). The histology of the limb at embryonic

337 stage E14.5 shows that the tibial anlagen is not only shorter in Nabo, but also lacks a

338 differentiated hypertrophic chondrocyte zone when compared with wildtype (Figure S4).

339

Nabo growth plate structure and chondrocyte dynamics

We analyzed the proximal tibia growth plates of 14-day old Nabo mice and compared

342 them to age-matched wildtype mice because at this stage growth rate in the tibia is close to its

343 maximum, and therefore, we would expect differences in growth plate structure to be most

344 apparent (Figure 3). Overall, the total growth plate was significantly taller than wildtype, by

$34531.6 \%$ (ANCOVA, F=33.434, $\mathrm{p}<0.001$ ). Similarly, the proliferative and hypertrophic zones were

346 significantly taller than wildtype, respectively by $42.8 \%$ (ANCOVA, $F=24.363, p<0.001)$ and by

$34725.0 \%($ ANCOVA, $F=22.586, p<0.001)$. The resting zone showed no difference in height (Figure

348 4a, Table 4). The proximodistal height of the last hypertrophic chondrocyte adjacent to the

349 chondro-osseous junction (COJ) is shorter in Nabo mice compared to wildtype mice by $12.1 \%$

350 (ANCOVA, F=6.454, $\mathrm{p}=0.025)$ (Figure 4b, Table 4).

351 The growth plate of Nabo shows defects at the chondro-osseous junction but not in the

352 general columnar organization of chondrocytes (Figure 5). The trabecular bone in the metaphysis

353 lacks clear longitudinal organization of the trabeculae and is generally more sparse than in 
354 wildtype mice (see below). The COJ is separated from the hypertrophic zone by a zone rich in

355 bone marrow cells. Many specimens show cartilage matrix, as indicated by the presence of

356 Alcian stain, with apparently healthy chondrocytes partially or completely enclosed within

357 trabecular bone (Figure 5c).

358 We performed a cell proliferation assay to determine whether proliferative chondrocytes

359 were actively dividing in the growth plates of Nabo mice. BrdU positive cells were present in the

360 growth plate, suggesting active chondrocyte proliferation. However, in contrast to wildtype mice,

361 BrdU positive cells were mostly concentrated in the resting zone and in the most proximal

362 proliferative chondrocytes (Figure 6a,b). Immunohistochemistry of Sox9 mirrors the BrdU

363 results, with Sox9 positive cells restricted to the most proximal proliferative zone (Figure 6c,d).

364 Immunohistochemistry of Runx2 shows positive cells in the presumptive pre-hypertrophic zone

365 (Figure 6e,g) and in the metaphysis (Figure 6f,h) suggesting that the phenotype is not caused by

366 an absence of osteoblasts.

367

368 Nabo trabecular architecture

369 In histology slides of proximal tibiae of 14-day-old pups, we observed sparse trabecular

370 bone in Nabo in comparison with age-matched wildtypes (see above, and Figure 5). We then

371 investigated whether the trabecular bone in the groups was similar at skeletal maturity. We $\mu \mathrm{CT}$

372 scanned tibiae for each group $(n=4-5$ each) and analyzed the proximal trabecular bone and the

373 cross-sectional properties using BoneJ $(18,24)$. Bone volume (BV) was significantly lower in

374 Nabo mice than in wildtype by $42.3 \%$ (ANCOVA, $\mathrm{F}=7.737, \mathrm{p}=0.027$ ), and, because total

375 endosteal volume (TV) was only $18.8 \%$ smaller in Nabo, this produced a bone volume ratio

$376(\mathrm{BV} / \mathrm{TV})$ that was also significantly lower in Nabo mice, by $28.6 \%$ compared to wildtype 
377 (ANCOVA, $\mathrm{F}=29.048, \mathrm{p}=0.001$ ). The trabeculae in Nabo mice are also thinner by $20 \%$

378 compared to the wildtype group (Tb.Th, ANCOVA, $F=46.517, p<0.001$ ) (Table 5). These adult

379 data are consistent with our early postnatal histological observations (Figure 5).

380 We measured the cross-sectional area (CSA), mean thickness (MT) of the diaphyseal 381 cortex, and the polar section modulus $\left(\mathrm{Z}_{\mathrm{pol}}\right)$, a measure of the distribution of bone from the 382 central axis of the bone diaphysis (Young et al., 2014). $Z_{\text {pol }}$ is $21.6 \%$ higher in Nabo than in 383 wildtype, but we did not find statistical differences in any these measurements between the 384 groups. We also calculated the index of robusticity (IR) as polar section modulus scaled to body 385 mass and tibia length. IR can be considered as the bending strength of the tibia of each mouse 386 (Young et al., 2014). IR is 58\% higher in Nabo compared to the wildtype group (ANCOVA, $387 \mathrm{~F}=77.807, \mathrm{p}<0.001$ ), which suggests that, at least from a bone geometry perspective, Nabo mice 388 are more resistant to bending loads (Table 5).

\section{Discussion}

\section{Nabo mice show a previously uncharacterized SD-like phenotype}

The Nabo mice present a peculiar skeletal phenotype that, based on the pedigree (Figure

393 S1), appears to be autosomal recessive. The phenotype affects proximal limb elements more

394 strongly than autopods (Figure 1). Additionally, Nabo mice exhibit a pronounced kyphosis and 395 frequent extra thoracic vertebrae (Figure 1c, Figure 2b). Because we did not find size differences 396 in bones that develop via intramembranous ossification (such as the clavicle and palatine bone in 397 the skull) (de Beer, 1937), we tentatively conclude that the phenotype derives primarily from 398 differences in cell and molecular mechanisms of endochondral ossification. 
400 bone formation and development, such as short bowed limbs, kyphosis, and vertebral anomalies

401 (Hurst, Firth \& Smithson, 2005). The growth plate also shows irregularities in bone and cartilage 402 matrix at the chondro-osseous junction that may contribute to this phenotype. However, there are 403 several major differences between the Nabo phenotype and known forms of SD (Table S2).

404 Notably, Nabo mice lack severe head and facial dysmorphologies and other clinical symptoms 405 (including brachydactyly or growth plate disorganization) that characterize many SDs (Krakow 406 \& Rimoin, 2007; Hurst, Firth \& Smithson, 2005). This suggests that Nabo is not caused by 407 mutations in major signaling pathways such as FGFs, BMPs and Wnt, or matrix proteins such as 408 collagen and aggrecan (Krakow \& Rimoin, 2007; Rimoin et al., 2007), which often leads to 409 craniofacial phenotypes.

410 We surveyed the Online Mendelian Inheritance in Man (OMIM) database

411 (www.omim.org) to identify potential human disorders with similarities to the Nabo phenotype.

412 Using the keyword "bowed" as our search term, we found 238 results, of which three skeletal 413 dysplasias with unknown etiologies presented similar clinical signs to our phenotype (Figure 7):

414 spondylometaphyseal dysplasia (OMIM 607543) (Kozlowski \& Poon, 2003), metaphyseal 415 acroscyphodysplasia (OMIM 250215) (Verloes et al., 1991) and metaphyseal dysostosis (OMIM 416 250420) (Rimoin \& McAlister, 1971). The remaining disorders differ significantly from our 417 phenotype because they exhibit severe craniofacial defects, fall under the category of 418 osteogenesis imperfecta, had no short limb phenotype, only showed a subset of the Nabo 419 phenotype defects, or show other defects not seen in the Nabo phenotype. Based on these results, 420 we may tentatively exclude most of the known genetic causes of well-characterized SDs 
421 phenotypes (Krakow \& Rimoin, 2010; Ballock \& O’Keefe, 2003; Hurst, Firth \& Smithson,

422 2005) as the basis of the Nabo mutation.

423

424 The Nabo phenotype may involve dysregulation of limb initiation and patterning

425 Our data show that mice at embryonic stage E14 already demonstrate the Nabo

426 phenotype, indicating that this phenotype must appear earlier in development. At E14, the

427 stylopod and zeugopod have already formed as cartilage anlagen while the autopod is still mostly

428 composed of undifferentiated mesenchymal cells (Taher et al., 2011). Because more proximal

429 limb elements are more strongly affected in Nabo, and because the frequent extra thoracic

430 vertebrae suggest dysregulation of somitogenesis, the Nabo phenotype may appear as early as

431 limb initiation and patterning. This is further supported by our observations of incomplete

432 differentiation of chondrocytes in both the tibial anlagen at embryonic stage E14.5 and within the

433 postnatal growth plate in Nabo, suggesting that Nabo chondrocytes do not differentiate as in the

434 wildtype mice.

435 The presence of the extra thoracic vertebra (if it is the same mutation) also suggests a

436 possible gradient regulation or specific time point dysregulation during somitogenesis (Dubrulle

437 \& Pourquié, 2004). The number of lumbar, sacral and caudal vertebrae does not differ, with extra

438 vertebrae appearing only in the thoracic region (Figure 2).

439 We have identified differences in Sox9 protein distribution in the tibial growth plate, but

440 the mechanism behind the Nabo phenotype is still unclear. Gene expression analysis and

441 genotyping will be essential to narrow down the genetic causes of this phenotype, and to

442 understand how the cause of this rare variant fits into the skeletal development program. Further

443 investigation of this unique mutant line has the potential to shed light on poorly-understood but 
444 critical aspects of limb development not accounted for by the major signaling pathways which

445 have been the focus of most research to date. Nabo may share a genetic basis with one or more

446 rare skeletal dysplasias, making it a promising model to understand these disorders as well.

447

\section{Conclusions}

449 The Nabo mutation represents a novel type of skeletal dysplasia with specific defects consistent 450 with a dysregulation of endochondral ossification. This mutation is autosomal recessive with 451 viable homozygotes facilitating ease of establishing and maintaining mutant lines. Nabo mice

452 show short bowed limbs and mild axial defects as well as changes in growth plate morphology

453 and reduction in trabecular bone, but show normal formation of intramembraneous skeletal

454 elements. The novel phenotype and specificity of the defects observed suggests that the Nabo 455 mouse may provide novel insights into less-understood aspects of endochondral ossification as 456 well as skeletal dysplasias more broadly.

457

\section{Acknowledgements}

459 The authors thank the staff at the University of Calgary Health Sciences Animal Resource Center

460 for the care provided to our mouse samples. Thanks also to John Matyas and Dragana Ponjevic

461 for assistance with histological analyses, Jason Anderson and Jessica Theodor for access to the

462 SkyScan uCT scanner, and Alexandra Dowhanik for E18 wildtype samples. Rebecca Green,

463 David Katz and Jason Pardo provided feedback on earlier versions of the manuscript, and their

464 help is gratefully acknowledged.

465

466 
467 List of abbreviations:

468 BrdU: Bromo-2'-deoxyuridine

469 BV: bone volume

$470 \mathrm{BV} / \mathrm{TV}$ : bone volume fraction (i.e., bone volume/total volume)

471 CSA: cross-sectional area

472 IR: robusticity

473 MT: mean thickness of the diaphyseal cortex

$474 \mu \mathrm{CT}$ : micro-computed tomography

475 OMIM : Online Mendelian Inheritance in Man

476 SD: Skeletal dysplasia

477 Tb.Th: trabecular thickness

478 TV: total volume

$479 Z_{\text {pol }}$ : polar section modulus

480

481

482 References

483 Baker KM, Olson DS, Harding CO, Pauli RM. 1997. Long-term survival in typical thanatophoric 484 dysplasia type 1. American Journal of Medical Genetics Part A 70, 427-436.

485 Ballock RT, O'Keefe RJ. 2003. Physiology and pathophysiology of the growth plate. Birth 486 defects research. Part C, Embryo today : reviews 69, 123-143.

487 Barbosa-Buck CO, Orioli IM, da Graça Dutra M, Lopez-Camelo J, Castilla EE, Cavalcanti DP. 488 2012. Clinical epidemiology of skeletal dysplasias in South America. American Journal of 489 Medical Genetics Part A 158, 1038-1045. 
490 Beals RK, Horton W. 1995. Skeletal dysplasias: An approach to diagnosis. Journal of the

491 American Academy of Orthopaedic Surgeons 3, 174-181.

492 Cosman MN, Sparrow LM, Rolian C. 2016. Changes in shape and cross-sectional geometry in

493 the tibia of mice selectively bred for increases in relative bone length. Journal of Anatomy 220, $494940-951$.

495 de Beer, GR. 1937. The development of the vertebrate skull. Oxford University Press, Oxford.

496 Doube, M. Kłosowski MM, Arganda-Carreras I, Cordelières FP, Dougherty RP, Jackson JS,

497 Schmid B, Hutchinson JR, Shefelbine SJ. 2010. BoneJ: Free and extensible bone image analysis

498 in ImageJ. Bone 47, 1076-1079.

499 Dubrulle J, Pourquié O. 2004. Coupling segmentation to axis formation. Development 131, $500 \quad 5783-5793$.

501 Eames BF, de la Fuente L, Helms J. 2003. Molecular ontogeny of the skeleton. Birth defects 502 research. Part C, Embryo today : reviews 69, 93-101.

503 Farooq S, Leussink S, Sparrow LM, Marchini M, Britz HM, Manske SL, Rolian C. 2017.

504 Cortical and trabecular morphology is altered in the limb bones of mice artificially selected for 505 faster skeletal growth. Scientific Reports 7, 10527.

506 German RZ, Hertweck DW, Sirianni JE, Swindler DR. 1994. Heterochrony and sexual 507 dimorphism in the pigtailed macaque (Macaca nemestrina). American Journal of Physical 508 Anthropology 93, 373-380.

509 Gignac PM, Kley NJ, Clarke JA, Colbert MW, Morhardt AC, Cerio D, Cost IN, Cox PG, Daza 510 JD, Early CM, Echols MS, Henkelman RM, Herdina AN, Holliday CM, Li Z, Mahlow K,

511 Merchant S, Müller J, Orsbon CP, Paluh DJ, Thies ML, Tsai HP, Witmer LM. 2016. Diffusible 
512 iodine-based contrast-enhanced computed tomography (diceCT): an emerging tool for rapid,

513 high-resolution, 3-D imaging of metazoan soft tissues. Journal of Anatomy 228, 889-909.

514 Hall, B. K. 2005. Bones and cartilage: developmental and evolutionary skeletal biology.

515 Academic Press.

516 Hurst JA, Firth HV, Smithson S. 2005. Skeletal dysplasias. Fetal and Neonatal Genetics 10, 233517241.

518 Kozlowski K, Poon CCS. 2003. Distinctive spondylometaphyseal dysplasia in two siblings.

519 American Journal of Medical Genetics 116A, 304-309.

520 Krakow D, Rimoin DL. 2010. The skeletal dysplasias. Genetics in Medicine 12, 327-341.

521 Kronenberg HM. 2003. Developmental regulation of the growth plate. Nature 423, 332-336.

522 Marchini M, Sparrow LM, Cosman MN, Dowhanik A, Krueger CB, Hallgrimsson B, Rolian C.

523 2014. Impacts of genetic correlation on the independent evolution of body mass and skeletal size

524 in mammals. BMC Evolutionary Biology 14, 258-258.

525 Marchini M, Rolian C. 2018. Artificial selection sheds light on developmental mechanisms of

526 limb elongation. Evolution 72, 825-837.

527 Marsden CD, Ortega-Del Vecchyo D, O'Brien DP, Taylor JF, Ramirez O, Vilà C, Marques-

528 Bonet T, Schnabel RD, Wayne RK, Lohmueller KE. 2016. Bottlenecks and selective sweeps

529 during domestication have increased deleterious genetic variation in dogs. Proceedings of the

530 National Academy of Sciences 113, 152-157.

531 Orioli I, Castilla E, Barbosa-Neto J. 1986. The birth prevalence rates for the skeletal dysplasias.

532 Journal of Medical Genetics 23, 328-332.

533 Rimoin DL, McAlister WH. 1971. Metaphyseal dysostosis, conductive hearing loss, and mental

534 retardation: a recessively inherited syndrome. Birth Defects Original Article Series VII, 116-122. 
535 Rimoin DL, Cohn D, Krakow D, Wilcox W, Lachman RS, Alanay Y. 2007. The skeletal

536 dysplasias. Annals of the New York Academy of Science 1117, 302-309.

537 Schindelin J, Arganda-Carreras I, Frise E, Kaynig V, Longair M, Pietzsch T, Preibisch S,

538 Rueden C, Saalfeld S, Schmid B, Tinevez JY, White DJ, Hartenstein V, Eliceiri K, Tomancak P,

539 Cardona A. 2012. Fiji: an open-source platform for biological-image analysis. Nature Methods

$540 \quad 9(7), 676-682$.

541 Schneider CA, Rasband WS, Eliceiri KW. 2012. NIH Image to ImageJ: 25 years of image

542 analysis. Nature Methods 9 (7), 671-675.

543 Shah IP, Varghese B, Fernandes JA. 2017. Skeletal dysplasia. Surgery 35(1), 52-61.

544 Shirley ED, Ain MC. 2012. Kyphotic Deformities in Skeletal Dysplasias. Seminars in Spine

545 Surgery 24(3), 186-191.

546 Srinivas V, Shapiro IM. 2012. The Epiphyseal Growth Plate: The Engine That Drives Bone

547 Elongation. In: Preedy V. (eds) Handbook of Growth and Growth Monitoring in Health and

548 Disease. 1331-1349. Springer New York.

549 Stoll C, Dott B, Roth MP, Alembik Y. 1989. Birth prevalence rates of skeletal dysplasias.

550 Clinical Genetics 35, 88-92.

551 Taher L, Collette NM, Murugesh D, Maxwell E, Ovcharenko I, Loots GG. 2011. Global gene

552 expression analysis of murine limb development. PloS One 6, e28358-e28358.

553 Verloes A, Merrer ML, Farriaux JP, Maroteaux P. 1991. Metaphyseal acroscyphodysplasia.

554 Clinical Genetics 39, 362-369.

555 Wojtowicz JM, Kee N. 2006. BrdU assay for neurogenesis in rodents. Nature Protocols 1, 13995561405. 
559 Figures, tables and supplementary files

560

561

Figure Legends

562 Figure 1. Nabo adult morphology. a. Wildtype and Nabo mice skinned and stained with Lugol's

563 iodine. The mice were $\mu \mathrm{CT}$ scanned and visualized with Amira v 5.4.2. b.c. 3D surface models

564 of forelimb, sternum and hind limbs in wildtype (b) and Nabo (c) derived from uCT scans. Scale 565 bar $=10 \mathrm{~mm}$.

566

567 Figure 2. E18 fetal mice and prenatal growth trajectories. a.b. Samples stained using Alcian blue 568 and Alizarin red. Scale bar $=1 \mathrm{~mm}$. Wildtype and Nabo forelimbs of mice at developmental stage 569 E18 (a). Example of extra rib expressed unilaterally in Nabo mice (black arrow, b). c.d.e.f.

570 prenatal growth of humerus (c), ulna (d), femur (e) and tibia (f) at developmental stage E14 and 571 E18 and neonatal (P0). Wildtype: dashed grey lines and Nabo: solid red lines. Vertical bars 572 indicate $95 \%$ confidence intervals.

573

574 Figure 3. Postnatal growth curve for cranial (a), forelimb (b-f) and hind limb (g-i) skeletal 575 elements in wildtype and Nabo. The curves were obtained by fitting a Gompertz logistic growth 576 function. Insets indicate growth rates, based on the first derivative of the Gompertz function. 577 Wildtype: open circles, dashed lines, Nabo: red circle and lines.

578

579 Figure 4. Growth plate histomorphometry. a. Box plots of resting, proliferative, hypertrophic 580 zones, and total proximal tibial growth plate size. b. Box plots of terminal hypertrophic 
581 chondrocyte height. Wildtype in grey; Nabo in red. Box represents the 25 th and 75 th percentile;

582 black bars within boxes represent the median; whisker represents the non-outlier range and dots

583 represent outliers.

584

585 Figure 5. Histomorphometry. a.b.c. Histology of proximal growth plate tibia of 14 days old

586 wildtype (a), heterozygote (b) and Nabo (c). Inset illustrates the chondro-osseous junction in 587 Nabo growth plate.

588

589 Figure 6. Growth plate cell proliferation and immunostaining assays of proximal growth plate

590 tibiae of 14 days old mice. a,b, BrdU staining of wildtype (a) and Nabo (b), showing decreased

591 mitotic activity in the proliferating zone (pz) in Nabo compared with wildtype. c,d:

592 immunostaining against Sox9 in growth plates of wildtype (c) and Nabo (d). Sox9 protein shows

593 comparable distribution to BrdU staining, with increased staining in the upper proliferative zone

594 and resting zone (rz) relative to the lower pz in Nabo. e,f,g,h: immunostaining against Runx2 in

595 the growth plate and metaphysis of wildtype (e,f) and Nabo (g,h). The antibody is detected in

596 both samples at the transition zone between proliferating and hypertrophic chondrocytes (arrows

597 in e,g) and in osteoblasts in trabecular bone (arrows in f,h). Scale bar - $100 \mu \mathrm{m}$.

598

599 Figure 7. Pie chart of the 238 diseases resulting from the search in the OMIM database using 600 the keyword "bowed" (www.omim.org). Dark pink represents the percentage of diseases with 601 Nabo-like phenotype. Light pink represents the percentage of diseases with unclear phenotype.

602 Green represents the percentage of diseases where only some elements of the limbs were

603 affected. Light green represents the percentage of diseases without short bowed limbs, or which 
604 are embryonic/perinatal lethal. Dark blue represents the percentage of diseases associated with

605 osteogenesis imperfecta. Light blue represents the percentage of diseases that are characterized

606 by craniofacial defects as well as limb bone defects.

607

608

Table Legends

609

610

Table 1. Least squared means (mm) of linear measurements of skull elements derived from $\mu \mathrm{CT}$

611 scans, adjusted for covariation with body mass. Standard error presented in parentheses. Asterisk

612 and bold font indicate statistically significant differences in group means $(\mathrm{p}<0.05)$. Foramen

613 magnum (FM). Df indicates degree of freedom. F indicates F-test (ANCOVA). p indicates p-

614 value.

615

616 Table 2. Means (mm) of bone collar size of E18 Nabo mice and wildtype. Standard error

617 presented in parentheses. Asterisk denotes significant differences in means $(p<0.05)$. Df

618 indicates degree of freedom. F indicates F-test (ANOVA). $p$ indicates p-value.

619

620 Table 3. Least squared means $(\mu \mathrm{m})$ of cartilage size of E14 Nabo mice and wildtype. Mean of

621 eyes and nose width were used as covariates for statistical analysis. Standard error presented in

622 parentheses. Asterisk and bold font denote statistically significant differences in group means (p

$623<0.05$ ). Df indicates degree of freedom. F indicates F-test (ANCOVA). p indicates p-value.

624

625 Table 4. Least squared means of growth plate zone size using histomorphometry, adjusted for

626 covariation with body mass. Standard error presented in parentheses. Asterisk and bold font 
627 denote statistically significant differences in means between groups $(\mathrm{p}<0.05)$. Df indicates

628 degree of freedom. F indicates F-test (ANCOVA). p indicates p-value.

629

630 Table 5. Means of cortical and trabecular bone variables. Standard error presented in

631 parentheses. Asterisk and bold font denote significant differences in means between groups $(\mathrm{p}<$ 632 0.05). .). Df indicates degree of freedom. F indicates F-test (ANCOVA). $p$ indicates p-value.

\section{Supplemental Data}

635

636 Supplemental Datafile 1: Excel spreadsheet containing raw skeletal and histological

637 measurements for all samples included in the study.

638

639 Supplemental Figure S1. Pedigree of the Nabo line. F indicates the generation of selection in 640 the Longshanks artificial selection experiment. Squares indicate males, circles indicate females.

641 The family name is indicated inside the squares and circles. The lines between the circles and

642 squares represent breeding pairs and subsequent progeny. Black circles and squares indicate

643 Nabo phenotype. Grey circles and squares are hypothesized heterozygotes. In F11, H2 male and 644 female are siblings.

645

646 Supplemental Figure S2. Skull morphology in wildtype and Nabo mice using $\mu \mathrm{CT}$ scanning. a.

647 Representation of the landmarks placed in the dorsal and ventral elements of the skull using

648 Amira. b.c. Dorsal and lateral view of a wildtype (b) and Nabo (c) specimen. Scale bar $=10 \mathrm{~mm}$. 649 
650 Supplemental Figure S3. Measurements taken using $\mu$ CT scanning with iodine contrast

651 staining. a.b.c. E14 embryo stained with Lugol's iodine, in coronal (a), parasagittal (b) and

652 transverse (c) section from $\mu \mathrm{CT}$. Outlines in c indicate limb cartilages. d. 3D render of forelimb

653 with humerus in cyan, radius in green and ulna in red. 3D-landmarks used for linear

654 measurements. e.f. 3D surface rendering of E14 embryo stained with Lugol's iodine. 3D-

655 landmarks in the nose (e) and eye (f) were used to derive internasal and interorbital distances,

656 respectively, as covariates.

657

658 Supplemental Figure S4. Histology of tibia anlagen at embryonic stage E14.5. (a,c) Tibia

659 anlagen (Tib) is shorter in Nabo (c) compared to wildtype (a). Portions of the fibula (Fib) and

660 femur (Fem) anlagen are also visible. (b,d) Histological features of tibia anlagen (magnified

661 region indicated by dashed boxes in a,c) showing fewer hypertrophic chondrocytes in Nabo (d).

662 Scale bar $=100 \mu \mathrm{m}$.

663

664 Supplemental Table S1. Mean of body mass and least square means of measurements taken

665 using $\mu \mathrm{CT}$. Standard error presented in parentheses. Bold font and asterisk denote statistically

666 significant differences in group means $(\mathrm{p}<0.05)$. Degree of freedom $(\mathrm{Df}), \mathrm{F}$ test $(\mathrm{F})$ and $\mathrm{p}$-value 667 (p).

668

669 Supplemental Table S2. Subset of non-lethal skeletal dysplasias. AD indicates autosomal

670 dominant, AR indicate autosomal recessive. EO indicates that the dysplasia interferes with

671 endochondral ossification, while IO indicates that the dysplasia interferes with intramembranous

672 ossification. 


\section{Table $\mathbf{1}$ (on next page)}

Least squared means $(\mathrm{mm})$ of linear measurements of skull elements derived from $\mu \mathrm{CT}$ scans, adjusted for covariation with body mass.

Standard error presented in parentheses. Asterisk and bold font indicate statistically significant differences in group means $(p<0.05)$. Foramen magnum (FM). Df indicates degree of freedom. $F$ indicates $F$-test (ANCOVA). $p$ indicates $p$-value. 
1 Table 1. Least squared means $(\mathrm{mm})$ of linear measurements of skull elements using $\mu \mathrm{CT}$ scanning.

2 Standard error presented in parenthesis. Asterisk and red font indicate statistical significant $(p<0.05)$.

3 Foramen magnum (FM). Df indicates degree of freedom. F indicates F-test (ANCOVA). $p$ indicates $p$ -

4 value.

Landmarks Wildtype

5

Sample size

Body mass (g)

Dorsal landmarks

Parietal length Land 1-2

Frontal length Land 2-3

Nasal length

FM height Land5-6

FM width

Skull length

Ventral landmarks

Occipital length

Occipital width Land2-3

Sphenoid length Land8-9

Palatine length

Palatine width

37.92
Land7-8

Land4-5

Land1-2

$5.042(0.098)$

6.581 (0.082)

4.081 (0.189)

$1.401(0.143)$

$3.633(0.063)$

$4.503(0.056)$

Land4-5

Land6-7
Nabo

5

31.23

$4.429(0.145)$

$4.423(0.145)$

$D f=1 ; F=0.001 ; p=0.997$

$7.443(0.144)$

$7.349(0.144)$

$D f=1 ; F=0.180 ; p=0.684$

$8.659(0.131)$

$8.246(0.131)$

$D f=1 ; F=4.293 ; p=0.077$

$4.184(0.072)$

$3.913(0.072)^{*}$

$D f=1 ; F=6.046 ; p=0.044$

$3.871(0.056)^{*}$

$D f=1 ; F=54.363 ; p<0.001$

$24.738(0.169)$

23.207 (0.169)

$D f=1 ; F=35.339 ; p=0.001$
$3.801(0.098)^{*} \quad D f=1 ; F=125.170 ; p<0.001$

$5.187(\mathbf{0 . 0 8 2})^{*} \quad D f=1 ; F=69.294 ; p<0.001$

$3.276(0.189)^{*} \quad D f=1 ; F=7.778 ; p=0.027$

$1.204(0.143)$

$D f=1 ; F=0.813 ; p=0.397$

$3.740(0.063)$

$D f=1 ; F=1.239 ; p=0.302$ 


\section{Table 2 (on next page)}

Means ( $\mathrm{mm}$ ) of bone collar size of E18 Nabo mice and wildtype. Standard error presented in parentheses.

Asterisk denotes significant differences in means $(p<0.05)$. Df indicates degree of freedom. $F$ indicates F-test (ANOVA). $p$ indicates $p$-value. 
1 Table 2. Means ( $\mathrm{mm}$ ) of bone collar size of E18 Nabo mice and wildtypes. Standard error

2 presented in parenthesis. Asterisk denotes significant differences in means $(p<0.05)$. Df

3 indicates degree of freedom. $F$ indicates F-test (ANOVA). $p$ indicates $p$-value.

4

Wildtype

Sample size

Humerus

Scapula

Sample size

Femur

Tibia

Ulna

6
5

$2.22(0.05)$

$1.75(0.05)$

5

1.65

$2.03(0.07)$

$2.33(0.06)$
Nabo

3

$1.18(0.09)^{*}$

$0.84(0.07)^{*}$

5

1.06

$1.62(0.07)^{*}$

$1.61(0.07)^{*}$
Statistics ANOVA

$D f=1 ; F=119.462 ; p<0.001$

$D f=1 ; F=114.993 ; p<0.001$

$D f=1 ; F=44.173 ; p<0.001$

$D f=1 ; F=16.096 ; p=0.004$

$D f=1 ; F=58.191 ; p<0.001$ 


\section{Table 3 (on next page)}

Least squared means $(\mu \mathrm{m})$ of cartilage size of E14 Nabo mice and wildtype.

Mean of eyes and nose width were used as covariates for statistical analysis. Standard error presented in parentheses. Asterisk and bold font denote statistically significant differences in group means $(p<0.05)$. Df indicates degree of freedom. $F$ indicates F-test (ANCOVA). $p$ indicates $p$-value. 
1 Table 3. Least squared means $(\mu \mathrm{m})$ of cartilage size of E14 Nabo mice and wiltypes. Mean of

2 eyes and nose width were used as covariates for statistical analysis. Standard error presented in

3 parenthesis. Asterisk and red font denote significant differences in means ( $p<0.05)$. Df

4 indicates degree of freedom. F indicates F-test (ANCOVA). $p$ indicates $p$-value.

5

6

\section{Wildtype}

Sample size

Mean eyes width $(\mu \mathrm{m})$

Mean nose width $(\mu \mathrm{m})$

Femur $(\mu \mathrm{m})$

Tibia $(\mu \mathrm{m})$

Humerus $(\mu \mathrm{m})$

Ulna $(\mu \mathrm{m})$
6

802

573

894 (56)

745 (38)

$1330(46)$

1096 (50)
Nabo

5

704

550

$646(56)^{*}$

$580(38)$ *

$931(46)^{*}$

$805(50)^{*}$

\section{Statistics ANCOVA}

$D f=1 ; F=6.521 ; p=0.043$

$D f=1 ; F=6.276 ; p=0.046$

$D f=1 ; F=24.695 ; p=0.003$

$D f=1 ; F=10.935 ; p=0.016$ 


\section{Table 4 (on next page)}

Least squared means of growth plate zone size using histomorphometry, adjusted for covariation with body mass.

Standard error presented in parentheses. Asterisk and bold font denote statistically significant differences in means between groups $(p<0.05)$. Df indicates degree of freedom. $\mathrm{F}$ indicates F-test (ANCOVA). $\mathrm{p}$ indicates $\mathrm{p}$-value. 
1 Table 4. Least squared means of growth plate zone size using histomorphometry. Standard

2 error presented in parenthesis. Asterisk denotes significant differences in means $(p<0.05)$. ). Df

3 indicates degree of freedom. $F$ indicates F-test (ANCOVA). $p$ indicates $p$-value.

4

5

\section{Wildtype Nabo Statistics ANCOVA}

Growth Plate Zones

Sample size $\quad 16$

11

Body mass (g) $\quad 8.35 \quad 6.54$

Total growth plate $(\mu \mathrm{m}) \quad \mathbf{5 0 3 . 0 0}(\mathbf{2 2 . 2 8 )} \quad \mathbf{7 3 4 . 9 7}(\mathbf{2 8 . 1 9}) * \quad \mathrm{Df}=1 ; \mathrm{F}=33.434 ; p<0.001$

Resting zone $(\mu \mathrm{m}) \quad 53.77(3.61) \quad 61.72(4.56) \quad D f=1 ; F=1.501 ; p=0.232$

Proliferative zone $(\mu \mathrm{m}) \quad 201.22(16.93) \quad 351.658(21.41) * \quad D f=1 ; F=24.362 ; p<0.001$

Hypertrophic zone $(\mu \mathrm{m}) \quad 229.10(8.94) \quad 305.62(11.31)^{*} \quad D f=1 ; F=22.586 ; p<0.001$

Last Hypertrophic Height

Sample size

7

9

Body mass (g)

8.22

6.53

Last hypertrophic 6 chondrocyte height $(\mu \mathrm{m})$

$40.83(1.34)$

$35.88(1.15)^{*} \quad D f=1 ; F=6.454 ; p=0.025$ 


\section{Table 5 (on next page)}

Means of cortical and trabecular bone variables.

Standard error presented in parentheses. Asterisk and bold font denote significant differences in means between groups $(p<0.05)$. ). Df indicates degree of freedom. $F$ indicates F-test (ANCOVA). $p$ indicates $p$-value. 
1 Table 5. Means of cortical and trabecular bone variables. Standard error presented in

2 parenthesis. Asterisk denotes significant differences in means $(p<0.05)$. ). Df indicates degree

3 of freedom. $F$ indicates F-test (ANCOVA). $p$ indicates $p$-value.

4

5

Wildtype

Sample size

Body mass (mg)

Tibia length $(\mathrm{mm})$

Bone Volume (BV, $\mathrm{mm}^{3}$ )

Total Volume (TV, $\left.\mathrm{mm}^{3}\right)$

Bone Volume Fraction (BV/TV)

Trabeculae Thickness (Tb.Th, $\mathrm{mm}$ )

Cross-sectional Area (CSA, $\mathrm{mm}^{2}$ )

Polar Section Modulus (Zpol, $\mathrm{mm}^{3}$ )

Robusticity (IR, $\mathrm{mm}^{2} \mathrm{mg}^{-2 / 3}$ )

Mean Thickness (MT, mm)
4

37.04

17.03

$0.97(0.15)$

$2.71(0.29)$

$0.35(0.19)$

$0.060(0.001)$

0.95 (0.09)

$0.29(0.03)$

$1.5 * 10^{-5}\left(0.1 * 10^{-5}\right)$

$0.36(0.03)$
Nabo

5

27.81

11.28

$0.56(0.05)^{*}$

$2.20(0.21)$

$0.25(0.06) *$

$0.048(0.001)^{*}$

$1.02(0.06)$

$0.37(0.02)$

$3.6 * 10^{-5}\left(0.2 * 10^{-5}\right) *$

$0.35(0.02)$
Statistics ANCOVA

$D f=1 ; F=7.737 ; p=0.027$

$D f=1 ; F=2.082 ; p=0.192$

$\mathrm{Df}=1 ; \mathrm{F}=29.048 ; p=0.001$

$D f=1 ; F=46.517 ; p<0.001$

$D f=1 ; F=1.501 ; p=0.232$

$D f=1 ; F=3.867 ; p=0.090$

$D f=1 ; F=77.807 ; p<0.001$

$D f=1 ; F=0.275 ; p=0.616$ 


\section{Figure 1}

Nabo adult morphology.

a. Wildtype and Nabo mice skinned and stained with Lugol's iodine. The mice were $\mu \mathrm{CT}$ scanned and visualized with Amira v 5.4.2. b.c. 3D surface models of forelimb, sternum and hind limbs in wildtype (b) and Nabo (c) derived from uCT scans. Scale bar $=10 \mathrm{~mm}$. 

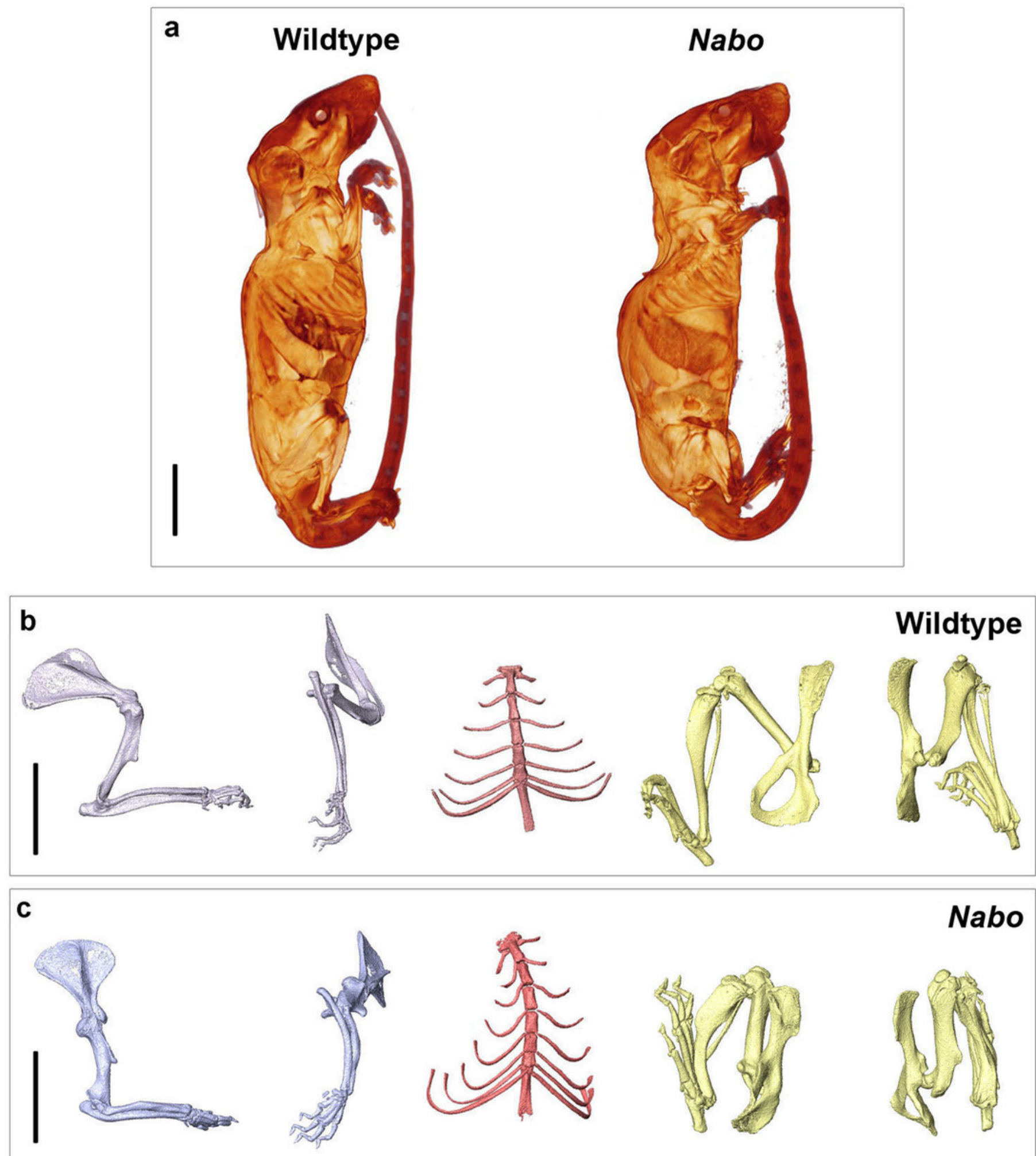


\section{Figure 2}

E18 fetal mice and prenatal growth trajectories

a.b. Samples stained using Alcian blue and Alizarin red. Scale bar $=1 \mathrm{~mm}$. Wildtype and Nabo forelimbs of mice at developmental stage E18 (a). Example of extra rib expressed unilaterally in Nabo mice (black arrow, b). c.d.e.f. prenatal growth of humerus (c), ulna (d), femur (e) and tibia (f) at developmental stage E14 and E18 and neonatal (P0). Wildtype: dashed grey lines and Nabo: solid red lines. Vertical bars indicate $95 \%$ confidence intervals. 

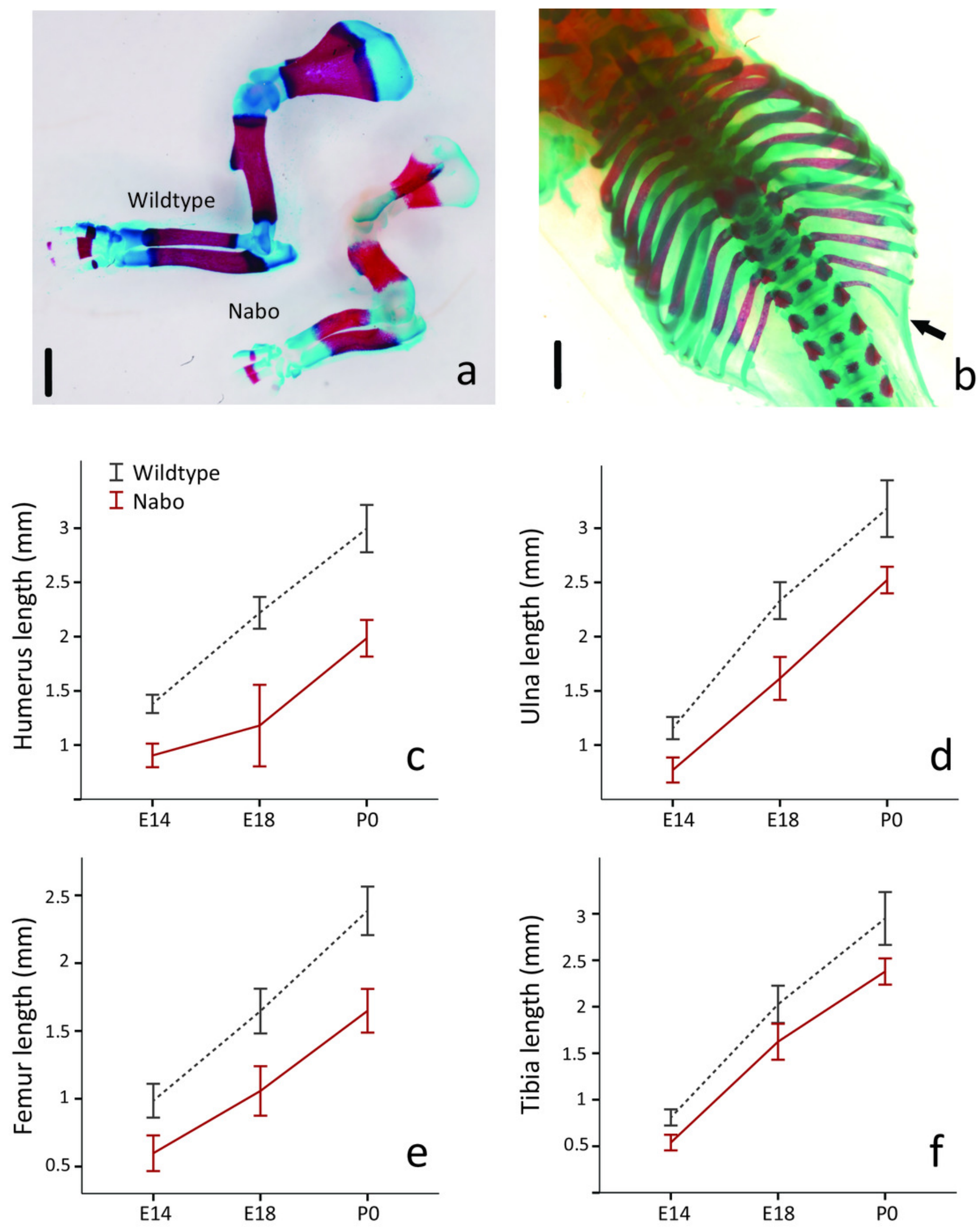
Figure 3

Postnatal growth curve for cranial (a), forelimb (b-f) and hindlimb ( $g$-i) skeletal elements in wildtype and Nabo

The curves were obtained by fitting a Gompertz logistic growth function. Insets indicate growth rates, based on the first derivative of the Gompertz function. Wildtype: open circles, dashed lines, Nabo: red circle and lines.
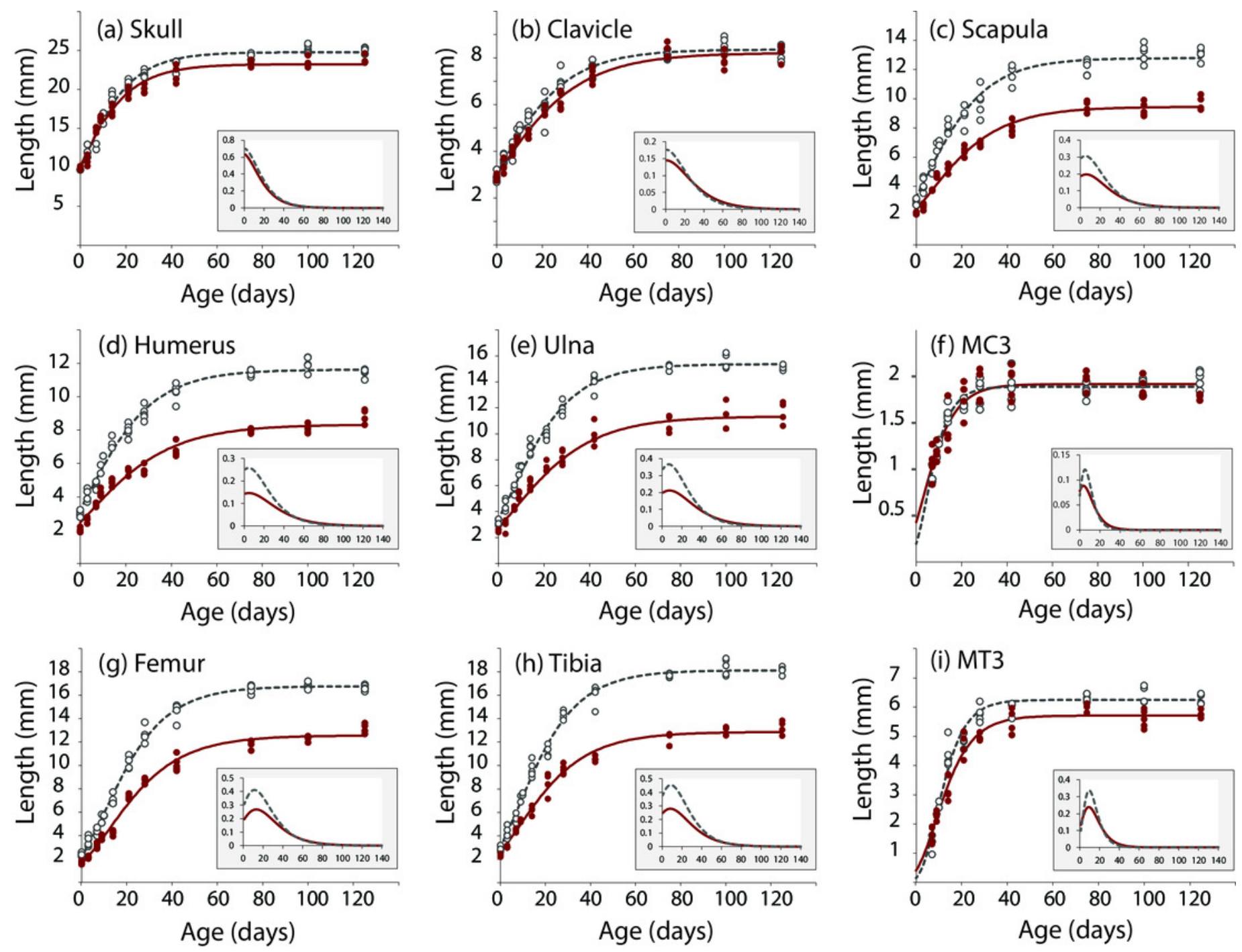
Figure 4

Growth plate histomorphometry.

a. Box plots of resting, proliferative, hypertrophic zones, and total proximal tibial growth plate size. b. Box plots of terminal hypertrophic chondrocyte height. Wildtype in grey; Nabo in red. Box represents the 25th and 75th percentile; black bars within boxes represent the median; whisker represents the non-outlier range and dots represent outliers.
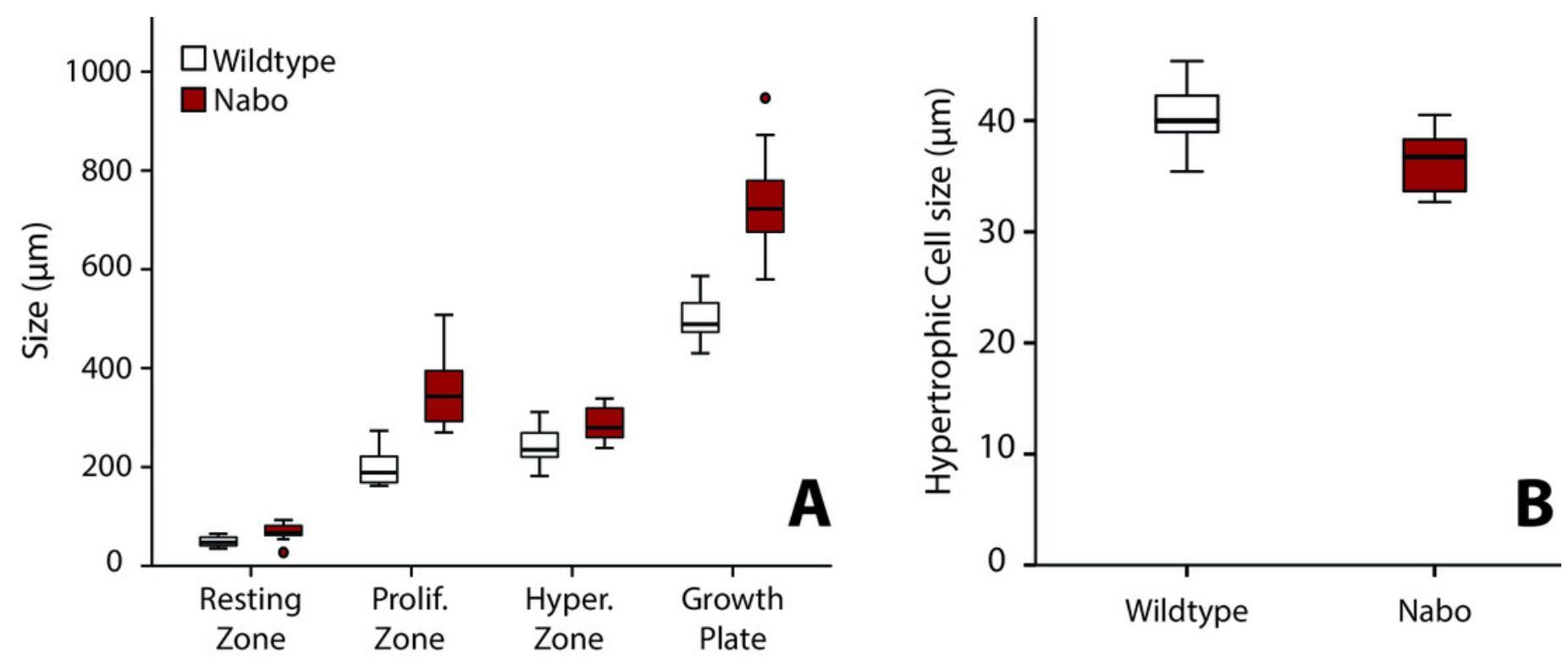
Figure 5

Histomorphometry

Histomorphometry. a.b.c. Histology of proximal growth plate tibia of 14 days old wildtype (a), heterozygote (b) and Nabo (c). Inset illustrates the chondro-osseous junction in Nabo growth plate.
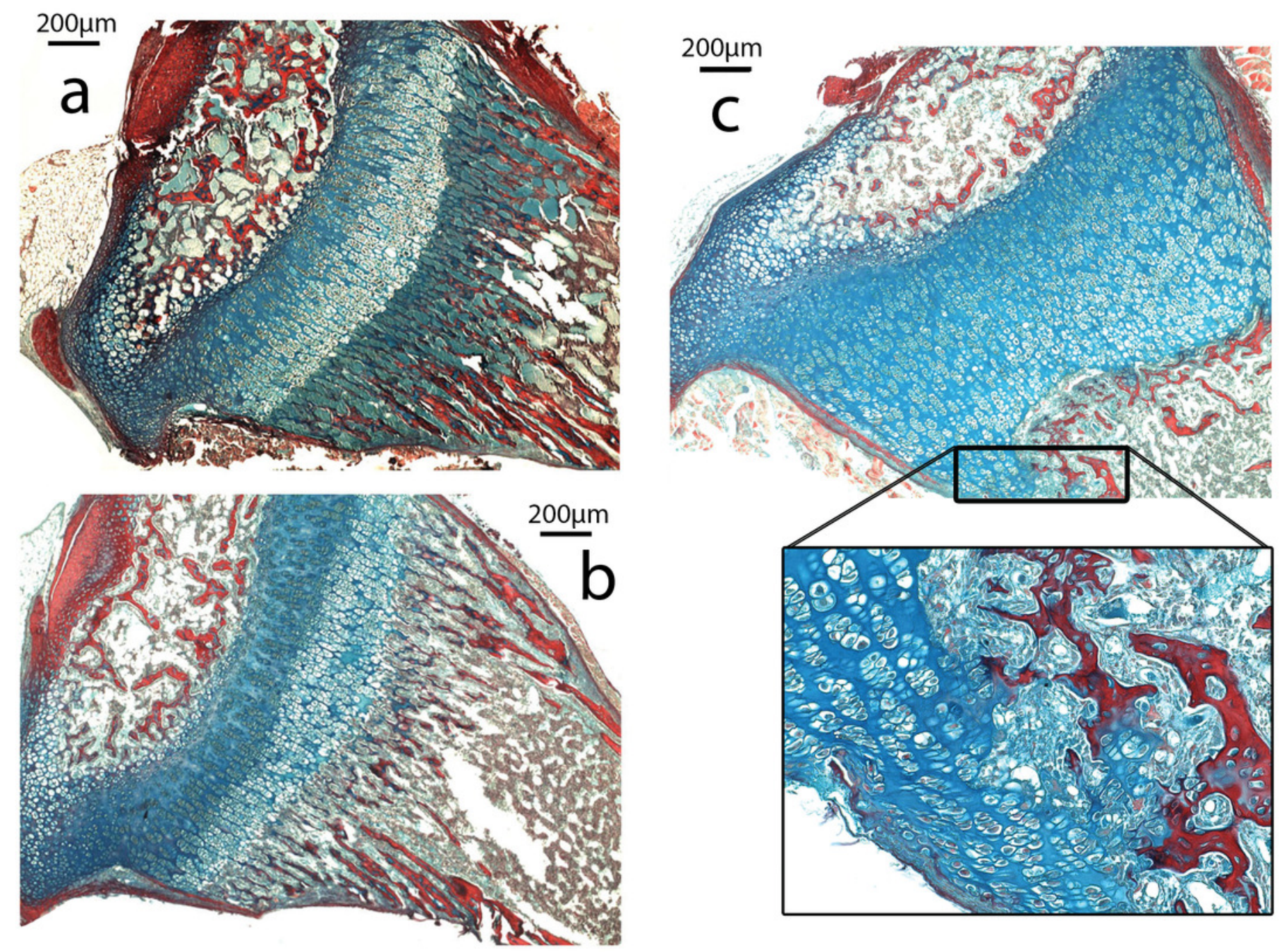


\section{Figure 6}

Cell Proliferation and Immunostaining Assays

Growth plate cell proliferation and immunostaining assays of proximal growth plate tibiae of 14 days old mice. a,b, BrdU staining of wildtype (a) and Nabo (b), showing decreased mitotic activity in the proliferating zone (pz) in Nabo compared with wildtype. c,d: immunostaining against Sox9 in growth plates of wildtype (c) and Nabo (d). Sox9 protein shows comparable distribution to BrdU staining, with increased staining in the upper proliferative zone and resting zone ( $r z$ ) relative to the lower pz in Nabo. e,f,g,h: immunostaining against Runx2 in the growth plate and metaphysis of wildtype $(e, f)$ and Nabo $(g, h)$. The antibody is detected in both samples at the transition zone between proliferating and hypertrophic chondrocytes

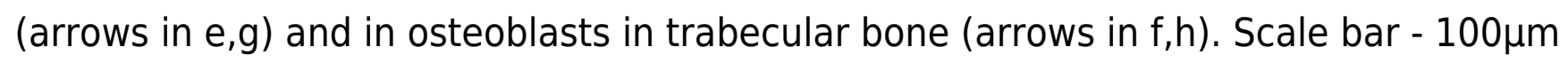




\section{wildtype}
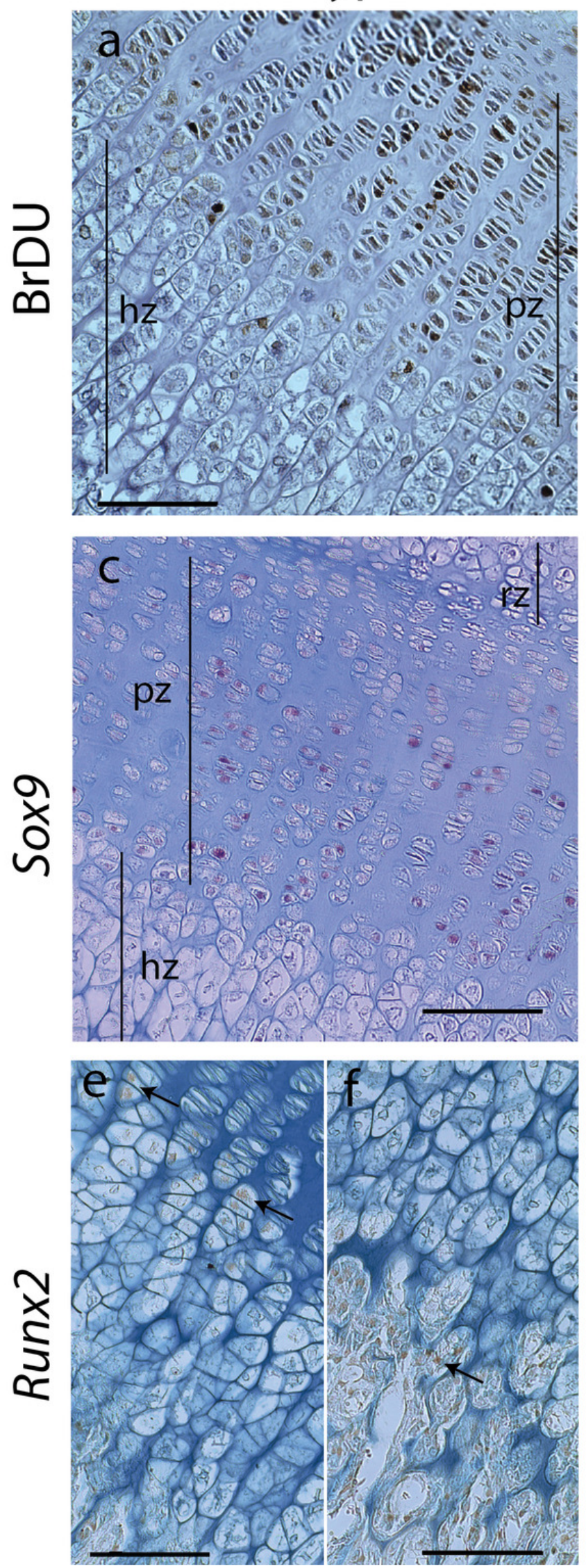

Nabo
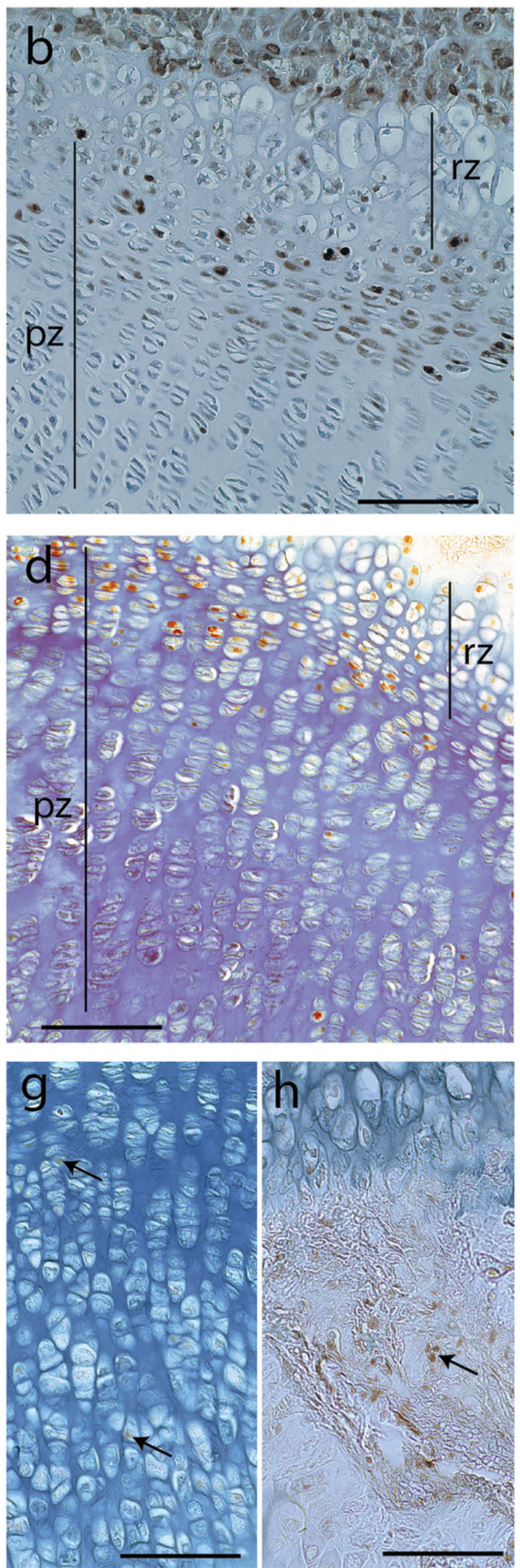


\section{Figure 7}

OMIM Skeletal Dysplasias

Pie chart of the 238 diseases resulting from the search in the OMIM database using the keyword "bowed" ( www.omim.org ). Dark pink represents the percentage of diseases with Nabo-like phenotype. Light pink represents the percentage of diseases with unclear phenotype. Green represents the percentage of diseases where only some elements of the limbs were affected. Light green represents the percentage of diseases without short bowed limbs, or which are embryonic/perinatal lethal. Dark blue represents the percentage of diseases associated with osteogenesis imperfecta. Light blue represents the percentage of diseases that are characterized by craniofacial defects as well as limb bone defects.

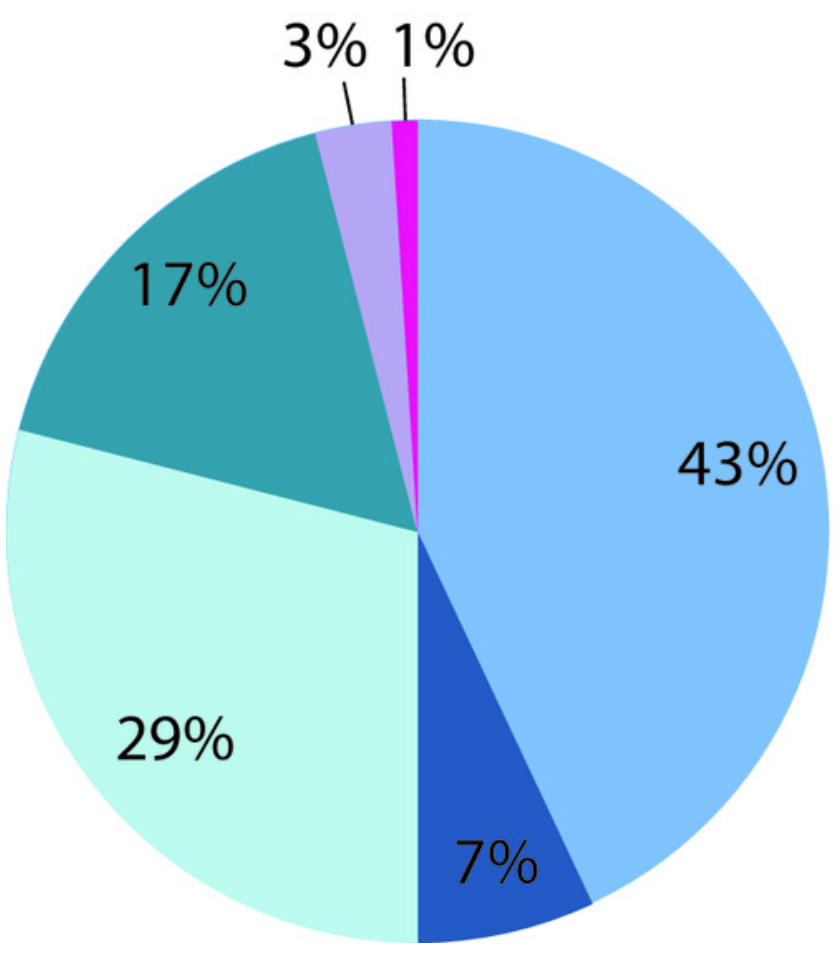

\section{Craniofacial defects}

No short/bowed phenotype and/or lethal

Partial overlap in affected elements

- Osteogenesis imperfecta

Phenotype unclear

Phenotype similar to Nabo 